\title{
Association between acute glaucoma and the weather and sunspot activity
}

\author{
JEFFREY S. HILLMAN AND JONATHAN D. C. TURNER \\ From the Department of Ophthalmology, St. James's Hospital, Leeds, and Corpus Christi College, \\ Cambridge
}

SUMMARY The dates of presentation of 191 cases of acute closed-angle glaucoma which presented at the Birmingham and Midland Eye Hospital between 1971 and 1974 were analysed and the seasonal incidence of acute glaucoma confirmed $(P<0 \cdot 001)$. These data were compared with meteorological data for air temperature, rainfall, hours of sunshine, atmospheric pressure, cloud amount, terrestrial magnetic field level, and sunspot numbers. A statistically significant direct association $(\mathrm{P}<0.05)$ was found with hours of sunshine and an inverse association $(\mathrm{P}>0.05)$ with cloud amount. A statistically significant inverse association $(\mathrm{P}<0.05)$ was found with sunspot count, and this assumed high significance $(P<0.0005)$ on consideration of sunspot activity in the preceding period. The literature is reviewed and the significance of these findings discussed.

Acute closed-angle glaucoma is the condition of rapid rise of intraocular pressure due to obstruction of the drainage angle of the anterior chamber, and it occurs most commonly in eyes with a particular anatomical configuration. Such eyes have a shallow anterior chamber (Rosengren, 1931) and tend to be hypermetropic (Lowe, 1964), with short eyeball length and increased axial lens thickness (Lowe, 1969) and steep anterior lens curvature (Lowe, 1972). Such ocular dimensions have a partial genetic basis, and this is the reason for racial variations in incidence. Such susceptible eyes may develop acute glaucoma in response to a variety of precipitating factors. Pupil block in the mid-dilated position is important and may result from the effect of mydriatic drugs or a low level of background illumination. In addition, emotional disturbance (Cohen and Hajioff, 1972), increased lens thickness with prolonged reading (Higgitt and Smith, 1955), and even sustained Yoga posture (Fahmy and Fledelius, 1973) have been blamed.

In clinical practice it is often observed that cases of acute glaucoma tend to occur in groups and appear to be commoner in the winter months. The

Presented in part to the Ophthalmological section of the Royal Society of Medicine on 10 June 1976

Address for reprints: J. S. Hillman, FRCS, Department of Ophthalmology, St. James's University Hospital, Leeds LS9 7TF latter phenomenon is traditionally attributed to the long, dark winter evenings, the implied cause being sustained pupil dilatation in the dark, but modern methods of illumination are so efficient as to cast doubt on this simple explanation. This apparent seasonal incidence has been confirmed in studies by Maynard (1908), Rohner (1927), Pillat (1933), and Weinstein (1934). Correlation between the incidence of acute glaucoma and various meteorological factors has been investigated by Steindorff (1902), Maynard (1908), Koike (1932), Brückner (1941), Schorn (1947), Sautter and Daubert (1955), Brezowsky and Kästner (1958), and Luner and Vašková (1964). The main positive findings in these studies, which were undertaken in different countries, are presented in Table 1 and show considerable differences, though there is the impression of association with cloudy weather and changing weather fronts. With the exception of the study by Sautter and Daubert (1955) the other workers appear to have inspected their data without formal statistical analysis. In all of these studies an important potential source of error lies in the apparent failure to correct data for the fact that acute glaucoma and weather factors independently exhibit seasonal variation, and this failure may falsely produce the appearance of association.

This study was undertaken to investigate the apparent seasonal incidence of acute glaucoma and to determine whether statistical analysis supports an 
Table 1 Summary of the principal findings in previous studies investigating the association between acute glaucoma and meteorological factors

\begin{tabular}{|c|c|c|c|c|c|c|c|c|}
\hline Author & Year & Country & Atmos. press. & Temp. & Rain & Clouds & Sun & Changeability \\
\hline Steindorff & 1902 & Germany & & $T$ & & & & \\
\hline Koike & 1932 & Japan & & & & + & $\dashv$ & \\
\hline Brückner & 1941 & Switzerland & & & & & & + \\
\hline Schorn & 1947 & Germany & & & & & & + \\
\hline Sautter and Daubert & 1955 & Germany & & & & & & + \\
\hline Luner and Vašková & 1964 & Czechoslovakia & + & & & & & \\
\hline
\end{tabular}

association between acute glaucoma and meteorological factors or with sunspot activity-a factor not previously studied in this context.

\section{Material and methods}

This study was made retrospectively on the 191 cases of acute closed-angle glaucoma which were treated at the Birmingham and Midland Eye Hospital between 1971 and 1974. In each case the diagnosis was confirmed by a review of the case records, and cases were ascribed to the date of onset of symptoms rather than the date of presentation at hospital. Published meteorological data from the records made at Edgbaston Observatory, Birmingham, were used, and the meteorological factors investigated were: (i) Daily mean air temperature $\left({ }^{\circ} \mathrm{C}\right)$, (ii) total rainfall $(\mathrm{mm})$, (iii) daily mean sunshine (hours), (iv) mean atmospheric pressure at mean sea level at 0900 GMT (mb), and (v) cloud amount at 0900 GMT (Oktas).

In addition, the provisional mean sunspot numbers (Rz) of Zürich Observatory were used for the investigation of sunspot activity, and variation in the level of the earth's magnetic field was investigated by considering the magnetic character figures (Cp) from the Geophysikalisches Institut of the University of Göttingen (Lincoln, 1971 onwards).

The data were analysed by the chi-squared method on a $2 \times 2$ box to determine whether the clinical impression of a seasonal incidence of acute glaucoma was supported and if there was an association with any single factor or combination of factors.

\section{Results}

The distribution of the 191 cases of acute glaucoma over the months of the year for the 4 years of the study is shown in Fig. 1. Simple inspection suggests an increased incidence in the winter months, and analysis shows this to be statistically significant $(\mathrm{P}<0.001)$, with a variation from year to year of lesser statistical significance $(P<0 \cdot 05)$. A seasonal incidence having been demonstrated, figures for the incidence of glaucoma were corrected to eliminate this seasonal variation by subtracting from each month's figure the mean value for that month over the four years studied. In a similar way the data for the meteorological factors studied were corrected to eliminate seasonal variation, and statistical analysis was performed.

No significant association was found between acute glaucoma and air temperature, atmospheric pressure, rainfall, or the level of the terrestrial magnetic field. A direct association of statistical significance $(\mathrm{P}<0.05)$ was found between acute glaucoma and daily mean sunshine (Fig. 2), and an inverse association $(P>0.05)$ was found with the 0900 GMT cloud amount.

The sunspot data did not require correction as sunspot activity is not seasonal but follows an 11year cycle. An inverse association of statistical

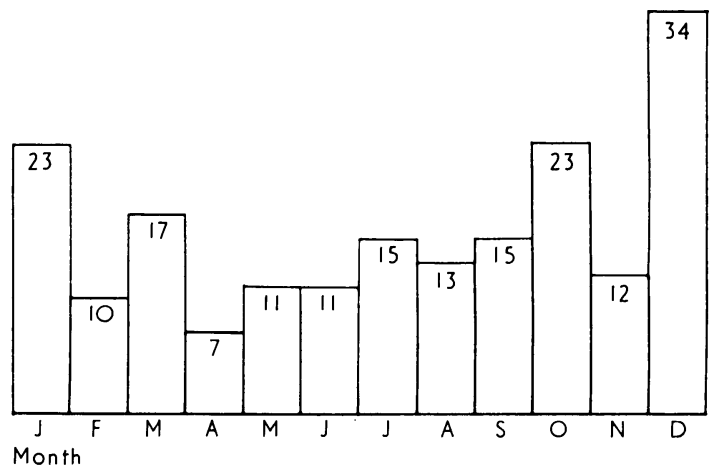

Fig. 1 Monthly distribution of 191 cases of acute glaucoma treated at Birmingham and Midland Eye Hospital between 1971 and 1974. Analysis confirms a seasonal incidence with statistical significance $(P<0 \cdot 05)$ 

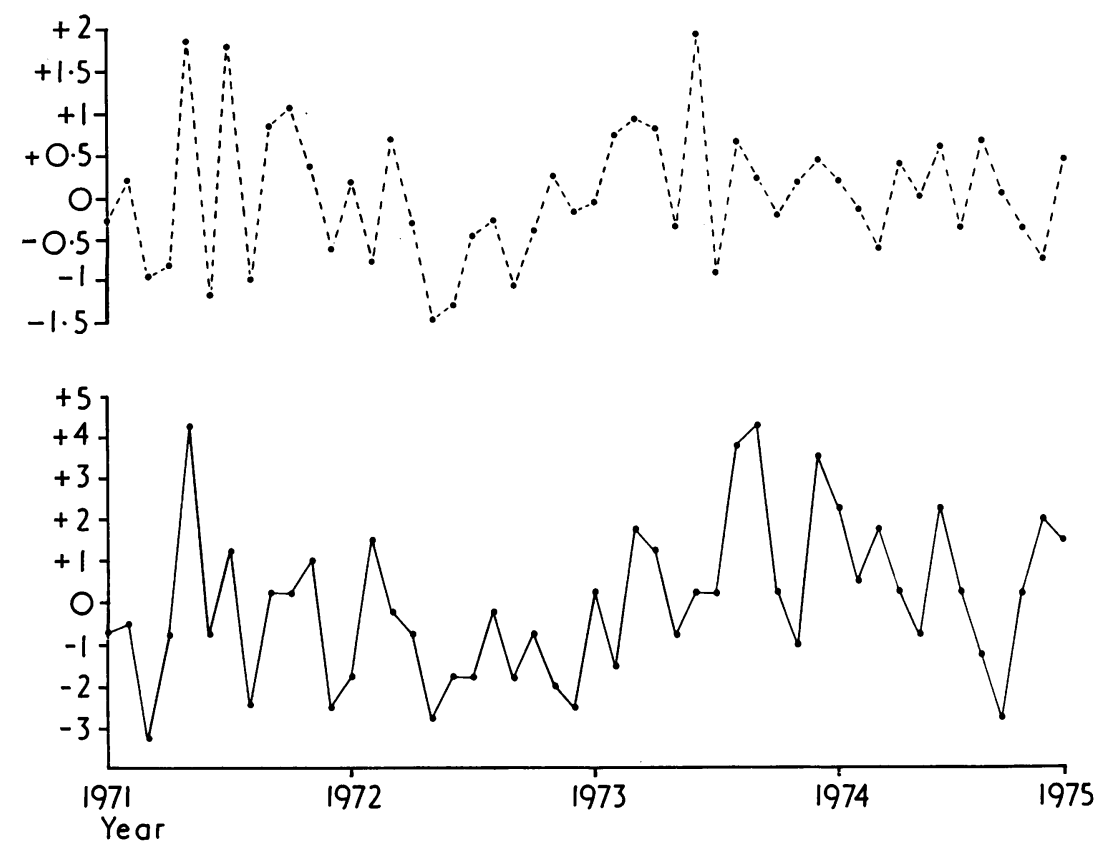

Fig. 2 Graphs showing the association between seasonally corrected acute glaucoma incidence (below) and seasonally corrected hours of sunshine (above), which on analysis show statistical significance $(P<0.05)$

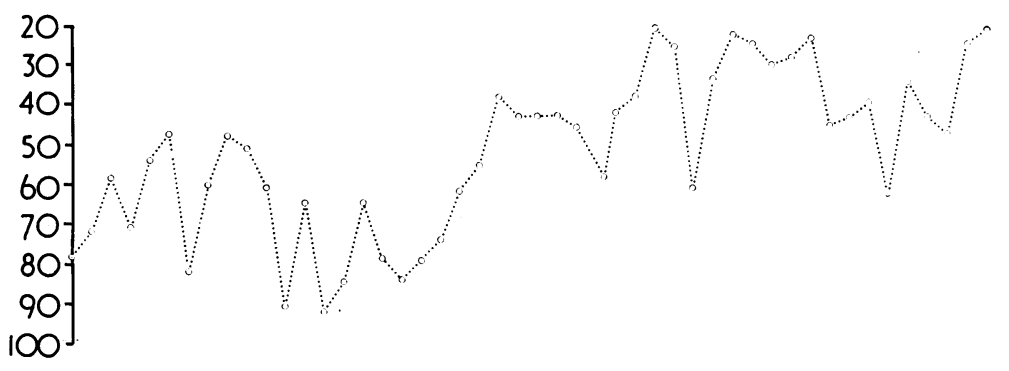

Fig. 3 Graphs showing the association between seasonally corrected acute glaucoma incidence (below) and sunspots

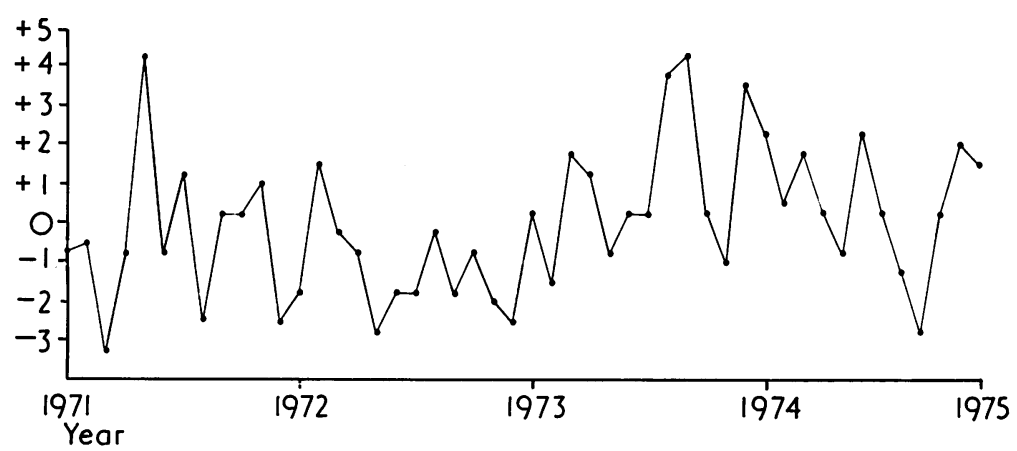
(above), which on analysis shows statistical significance $(P<0.05)$ and on consideration of sunspot activity in the preceding 4-week period shows greater significance $(P<0.0005)$

significance $(P<0.05)$ was found with the sunspot count (Fig. 3), and on considering the sunspot count for the preceding month the association assumed a greater significance of high statistical order $(\mathbf{P}<$ 0.0005 ). The incidence of acute glaucoma was then considered in relation to the preceding levels of the 5 meteorological factors studied without change in the level of statistical significance of association for any factor. The possible association between acute glaucoma and the degree of changeability of each of 
Table 2 Data for the incidence of acute glaucoma (seasonally corrected), sunspots (uncorrected), and sunshine (seasonally corrected) for 1971 to 1974 inclusive

\begin{tabular}{|c|c|c|c|c|c|c|c|}
\hline $\begin{array}{l}1971 \\
\text { Month }\end{array}$ & $\begin{array}{l}\text { Corrected } \\
\text { glaucoma }\end{array}$ & Sunspots & $\begin{array}{l}\text { Corrected } \\
\text { sunshine }\end{array}$ & $\begin{array}{l}1973 \\
\text { Month }\end{array}$ & $\begin{array}{l}\text { Corrected } \\
\text { glaucoma }\end{array}$ & Sunspots & $\begin{array}{l}\text { Corrected } \\
\text { sunshine }\end{array}$ \\
\hline $\begin{array}{l}\text { January } \\
\text { February } \\
\text { March } \\
\text { April } \\
\text { May } \\
\text { June } \\
\text { July } \\
\text { August } \\
\text { September } \\
\text { October } \\
\text { November } \\
\text { December }\end{array}$ & $\begin{array}{l}-0.75 \\
-0.50 \\
-3.25 \\
-0.75 \\
+4.25 \\
-0.75 \\
+1.25 \\
-2.25 \\
+0.25 \\
+0.25 \\
+1.00 \\
-2.50\end{array}$ & $\begin{array}{l}77 \cdot 9 \\
71 \cdot 5 \\
58 \cdot 2 \\
70 \cdot 7 \\
53 \cdot 8 \\
47 \cdot 1 \\
81 \cdot 7 \\
59 \cdot 9 \\
47 \cdot 5 \\
50 \cdot 8 \\
60 \cdot 5 \\
90 \cdot 3\end{array}$ & $\begin{array}{l}-0.26 \\
+0.21 \\
-0.96 \\
-0.82 \\
+1.85 \\
-1.17 \\
+1.80 \\
-0.99 \\
+0.85 \\
+1.08 \\
+0.38 \\
-0.64\end{array}$ & $\begin{array}{l}\text { January } \\
\text { February } \\
\text { March } \\
\text { April } \\
\text { May } \\
\text { June } \\
\text { July } \\
\text { August } \\
\text { September } \\
\text { October } \\
\text { November } \\
\text { December }\end{array}$ & $\begin{array}{l}+0.25 \\
-1.50 \\
+1.75 \\
+1.25 \\
-0.75 \\
+0.25 \\
+0.25 \\
+3.75 \\
+4.25 \\
+0.25 \\
-1.00 \\
+3.50\end{array}$ & $\begin{array}{l}42 \cdot 2 \\
42 \cdot 1 \\
45 \cdot 4 \\
57 \cdot 6 \\
41 \cdot 5 \\
37 \cdot 6 \\
20 \cdot 4 \\
25 \cdot 6 \\
60 \cdot 8 \\
33 \cdot 0 \\
22 \cdot 1 \\
24 \cdot 2\end{array}$ & $\begin{array}{l}-0.08 \\
+0.72 \\
+0.91 \\
+0.80 \\
-0.36 \\
+1.91 \\
-0.94 \\
+0.64 \\
+0.20 \\
-0.24 \\
+0.15 \\
+0.42\end{array}$ \\
\hline $\begin{array}{l}1972 \\
\text { Month }\end{array}$ & & & & $\begin{array}{l}1974 \\
\text { Month }\end{array}$ & & & \\
\hline
\end{tabular}

the meteorological factors was also investigated without statistically significant findings. Table 2 presents the data which were found on analysis to be significant.

\section{Discussion}

It is of interest that in this study no association was found between acute glaucoma and air temperature or atmospheric pressure, as these factors might have been considered the most likely to affect the eye via changes in the cardiovascular system. The direct association with hours of sunshine and smaller inverse association with cloud amount is the reverse of what might have been expected and suggests that contrast between day and evening levels of illumination may be a precipitating factor for a susceptible eye. From our results the seasonal variation in the incidence of acute glaucoma cannot be directly attributed to meteorological factors, although an indirect meteorotropic effect by means of behavioural changes such as diet, clothing, or level of physical activity still remains a possibility.

The inverse association of acute glaucoma with low sunspot activity and in particular the very strong association with low sunspot activity in the preceding month is interesting but difficult to explain, as knowledge about the interaction between sunspot activity and terrestrial parameters is incomplete.
Sunspots are cold areas on the surface of the sun which are associated with fluctuations in the intensity of the solar wind (a stream of ionised particles leaving the sun's surface) and with short bursts of $\gamma$ radiation from solar flares. They are not associated with variation in the sun's overall brightness or energy output. They possibly have a long-term effect on the earth's weather via the solar wind's ionisation of the upper atmosphere, which in turn may affect the formation of meteorological depressions. They are associated with fluctuations in the earth's magnetic activity. Although Friedman et al. (1963) have suggested there may be an association between psychiatric disease and terrestrial magnetic activity, and Schorn (1947) suggested that glaucoma attacks are commoner on days of earth magnetic calm, this study does not support such a mechanism for sunspot effect on the eye. It appears from the present study that further investigation into human responses to solar activity may be rewarding.

We thank the surgeons of the Birmingham and Midland Eye Hospital for permission to investigate their patients and Mr R. B. Hildred for the preparation of illustrative material.

\section{References}

Brezowsky, H., and Kästner, M. (1958). Medizinische Monatsschrift, 12, 538-542. 
Brückner, A. (1941). Schweizerische medizinische Wochenschrift, 71, 1242-1243.

Cohen, S. I., and Hajioff, J. (1972). Journal of Psychosomatic Research, 16, 335-341.

Fahmy, J. A., and Fledelius, H. (1973). Acta Ophthalmologica, $51,80-84$.

Friedman, H., Becker, R. O., and Bachman, C. H. (1963). Nature, 200, 626-628.

Higgitt, A., and Smith, R. (1955). British Journal of Ophthalmology, 39, 103-108.

Koike, T. (1932). Acta Societatis Ophthalmologicae Japonicae, 36. 140.

Lincoln, J. V. (1971 onwards). Journal of Geophysical Research, monthly data reports.

Lowe, R. F. (1964). British Journal of Ophthalmology, 48, 191-195.

Lowe, R. F. (1969). American Journal of Ophthalmology, 67, 87-93.
Lowe, R. F. (1972). British Journal of Ophthalmology, 56, 409-413.

Luner, J., and Vašková, M. (1964). Československa Oftalmologie, 20, 469-472.

Maynard, F. P. (1905). The Ophthalmoscope, 6, 864-865.

Pillat, A. (1933). Albrecht v. Graefes Archiv für Ophthalmolgie, 129, 229-322.

Rohner, M. (1927). Schweizerische medizinische Wochenschrift, 8, 780-787.

Rosengren, B. (1931). Acta Ophthalmologica, 9, 103-179.

Sautter, H., and Daubert, K. (1955). Ophthalmologica, 129, 381-389.

Schorn, J. (1947). Albrecht v. Graefes Archiv für Ophthalmolgie, 148, 121-128.

Steindorff, K. (1902). Deutsche medizinische Wochenschrift, 28, 929-932.

Weinstein, P. (1934). Klinische Monatsblätter für Augenheilkunde, 93, 794-797. 